\title{
Epigenética en el origen de la obesidad: perspectiva desde la célula grasa
}

\section{Jorge Abondano, Fernando Lizcano}

Centro de Investigación Biomédica Universidad de la Sabana

(CIBUS), Chía, CU, Colombia.

Correspondencia: Fernando Lizcano

Centro de Investigación Biomédica de la Universidad de la

Sabana. Campus del Puente del Común. Chía, CU.

Código postal: 250008; Tel 8615555 ext. 23907.

Palabras Clave: Obesidad, Epigenética, Tejido adiposo,

Expresión genética.

Conflicto de intereses: Los autores de este manuscrito manifiestan que no hay ningún conflicto de intereses en los resultados. Este manuscrito obedece a los criterios que impulsan el espíritu académico.

Fecha de recepción: 9/07/2017

Fecha de aceptación: 19/10/2017

\section{Resumen}

Las enfermedades crónicas no transmisibles son las entidades que tienen mayor repercusión en el sector salud a nivel global. Quizá una de las circunstancias que más se encuentra relacionada con el aumento progresivo en muchas de estas entidades es la obesidad. Las causas y posibles planes terapéuticos para la obesidad son complejos, por tal motivo deben ser enfocados desde diferentes tejidos en el organismo. Uno de estos enfoques sería la regulación del centro del hambre y la saciedad a nivel central, especialmente en el hipotálamo, otro es la forma como el individuo gasta su energía en las células musculares $\mathrm{y}$ un aspecto adicional es la forma en que las células adiposas almacenan y ahorran energía. En los últimos años se ha observado que los individuos adultos cuentan con diferentes tipos de células adiposas con origen germinal divergente. La presencia de estas células adiposas puede tener una variación fenotípica y en determinadas circunstancias podría presentar una función más termogénica de acuerdo con diferentes circunstancias ambientales. La influencia del ambiente se realiza mediante la modificación de genes específicos, que pueden determinar una variación funcional del hipotálamo, el músculo y el tejido adiposo. Estas modificaciones son denominadas epigenéticas, dado que no influyen sobre la estructura del ADN, pero cambian completamente su funcionalidad. En el presente trabajo hemos realizado un estudio de las circunstancias a través de las cuales el ambiente puede tener influencia en la aparición de la obesidad. Se ha realizado una búsqueda mediante las bases de datos de Pubmed, Evidencia Based Medicine, Science direct, Ovid, EBSCO, Proquest, Springer, desde enero del año 2012 hasta marzo del año 2017, buscando como palabras clave, obesidad, adipocito y los términos epigenética y ambiente.

\section{Introducción}

El aumento en la prevalencia de obesidad durante los últimos tres decenios ha sido sustancial, llegando a considerarse una epidemia de salud pública ${ }^{(1)}$. A nivel global, en el año 2014, la obesidad en la población mayor de 18 años fue de $15 \%$ en las mujeres y de $11 \%$ en los hombres. Más de 42 millones de niños menores de 5 años tenían sobrepeso en el 2013. (World Health Organization (WHO). Global Status Report on Non Communicable Diseases 2014. Switzerland: WHO; 2014) ${ }^{(2)}$.

La prevalencia de sobrepeso y obesidad en Estados Unidos de Norteamérica en el año 2014 fue mayor 62\% en mujeres adultas y $65 \%$ en hombres ${ }^{(3)}$. En nuestro país se ha realizado en forma reciente una Encuesta Nacional de Nutrición (ENCIN 2015), cuyos resultados están aún por ser socializados. No obstante, en reporte reciente se ha establecido que la prevalencia de sobrepeso y obesidad en el grupo de mujeres entre los 50 y 60 años llega al 69\%, mientras en el grupo de la misma edad en hombres es de 59\%. Estos son los grupos de edad con mayor problema en nuestro país ${ }^{(4,5)}$.

Los cuadros que presentan obesidad con un componente genético caracterizado son poco frecuentes. En general, se puede describir que el origen genético de la obesidad presenta dos formas, una sindrómica y otra no sindrómica. La forma sindrómica puede ser secundaria a rearreglos cromosómicos (síndrome de Prader-Willi, síndrome WAGAR, deficiencia SIM1) o por alteraciones pleiotrópicas (síndrome BardetBiedl, síndrome Frágil X, síndrome de Cohen). Las formas no sindrómicas de la obesidad pueden ser por mutaciones puntuales en ciertos genes de manera monogénica, caso de la proopiomelanocortina (POMC), receptor de leptina, receptor 4 de melanocortina (MC4R), FTO (proteína asociada a grasa), proconvertasa 1 (PC1) y receptor de Ghrelina ${ }^{(6)}$. Con los avances en las tecnologías genómicas podemos observar una compleja interacción de factores ambientales, absorción de ener- 
gía desequilibrada, las mutaciones genéticas, una microbiota intestinal aberrante $y$, especialmente, la epigenética ${ }^{(7,8)}$.

\section{Epigenética}

El término "epigenética" se introdujo en la década de los cuarentas por Waddington como un intento de definir el papel de la genética en los procesos de desarrollo ${ }^{(9)}$. La epigenética se refiere a la rama de la biología molecular perteneciente al estudio de las modificaciones que controlan la expresión génica sin cambios estructurales en la secuencia de ADN. Los fenómenos que afectan el normal funcionamiento de los genes en diversos tejidos con impactos diversos de acuerdo con su función suceden mediante la metilación de ADN, cambios postransduccionales de la histonas en la cromatina, y las modificaciones inducidas por el ARN de interferencia (miRNA ${ }^{(10)}$. Un cuerpo creciente de evidencia sugiere que la epigenética busca comprender las relaciones entre algunos genes blancos y ajustes ambientales (alimentación, sedentarismo, tabaquismo, tóxicos, etc.) para generar un fenotipo y conducir al desarrollo de diversas enfermedades, incluyendo el cáncer, la obesidad y la diabetes ${ }^{(11,12)}$.

\section{Metilación de ADN}

La metilación del ADN es un proceso reversible realizado por metiltransferasas de ADN (DNMTs) y desmetilasas de ADN.
La metilación de ADN implica la adición de un grupo metilo a la citosina en regiones específicas, llamadas islas CpG. La modificación de la metilación del ADN tiene influencia en la zona reguladora de la expresión de los genes (promotor). Áreas de actividad transcripcional menor, que se denomina heterocromatina, usualmente hipermetilados y sin expresión génica ${ }^{(13)}$.

\section{Modificaciones del nucleosoma}

Otras modificaciones que controlan la expresión de los genes son las denominadas postransduccionales de las histonas, que incluyen diferentes actividades enzimáticas tales como la acetilación, metilación, fosforilación, ubiquitinación, y sumolización, por supuesto tienen lugar en el núcleo de las células. Estos eventos enzimáticos efectúan un cambio de la unión de las histonas y la hebra de ADN en la región funcional de la cromatina, denominada nucleosoma. Las modificaciones enzimáticas pueden aumentar la unión de las histonas con el ADN y reducir la expresión de los genes o, por el contrario, pueden inducir una disminución de esta unión y aumentar la expresión de los genes.

Las enzimas responsables de las modificaciones de colas $\mathrm{N}$ terminal de H2A, H2B, H3 y H4 son histonas acetiltransferasas (HAT), deacetiltransferasas (HDAC), histonas metiltransferasas (HMTs) y las histonas demetilasas (HDM) ${ }^{(14,15)}$ (figura 1).

Figura 1. Cofactores que modifican enzimáticamente la función de ADN y la estructura del nucleosoma (mediante modificaciones de las histonas)

Algunos cofactores como acetil-CoA y alfa-ceto-glutarato que provienen del ciclo del ácido cítrico están sujetos a los niveles de glucosa y ácidos grasos KDM, demetilasa de lisina. HAT, acetil transferasa de histona. Algunos aminoácidos como triptófano y la vit B3 pueden controlar la actividad de NAD, adenina dinucleótido nicotinamida; SIRT, sirtruina; Los niveles de ácido fólico, vit B 12 pueden controlar la metionina, SAM, S-adenosil metionina; FAD, flavina adenina dinucleótido; PRMT, metiltransferasa de arginina; DNMT, metiltransferasa de ADN; KMT, metiltransferasa de lisina; LSD1, demetilasa específica de lisina.

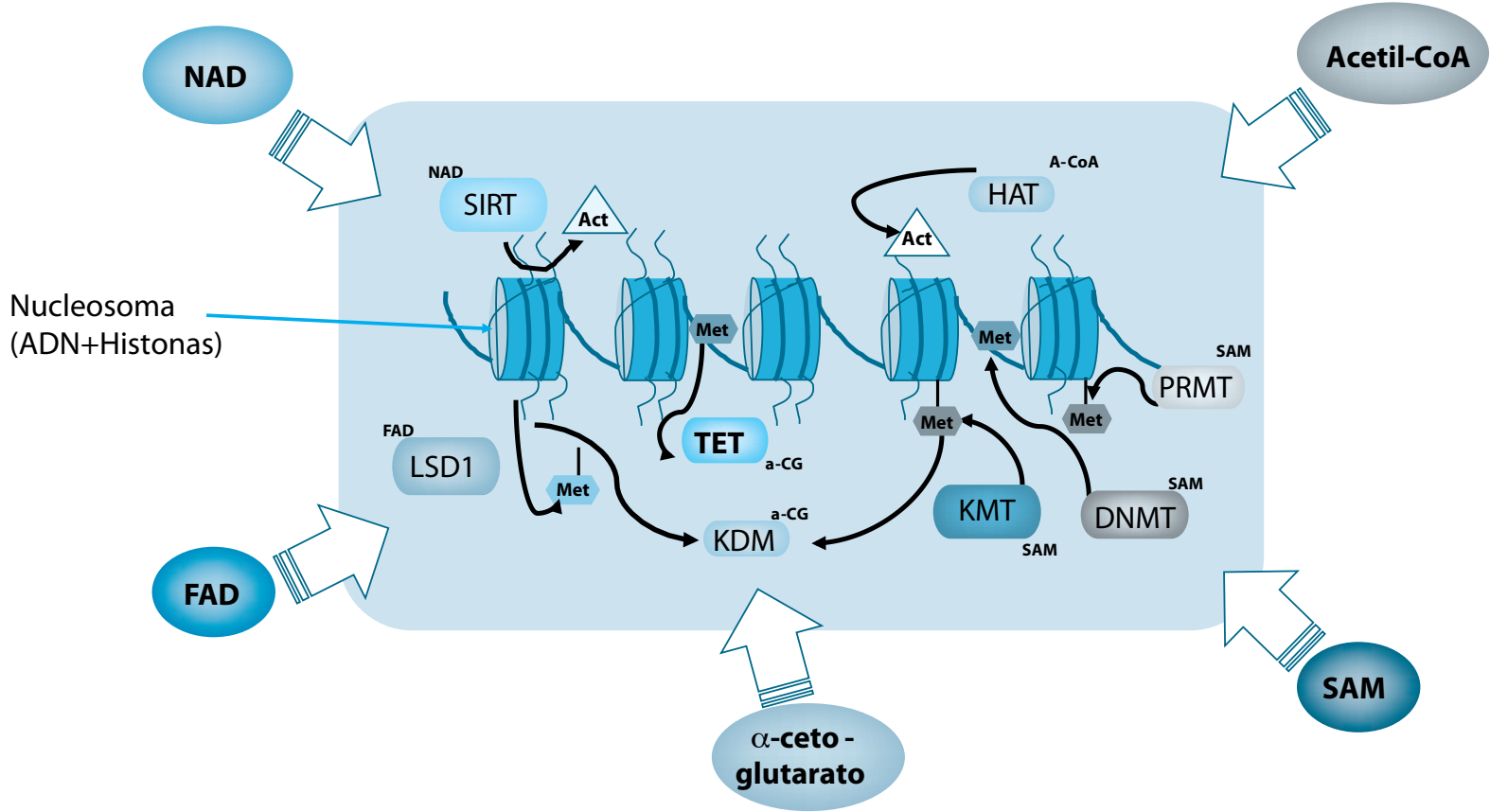




\section{ARN de interferencia}

ARNis son moléculas pequeñas, de aproximadamente 19 a 33 nucleótidos de longitud, derivados de transcritos endógenos que generan una estructura de horquilla, que interactúan con regiones específicas del ARNm. El emparejamiento entre ARNi y el ARNm genera inhibición de la traducción, como resultado de la degradación de ARNm y/o la desestabilización de la estructura del ARNm. La evidencia reciente identificó la participación de varios ARNis en la patogénesis de varias enfermedades, incluyendo la diabetes y la obesidad ${ }^{(16,17)}$.

\section{Tejido adiposo}

El tejido adiposo en humanos está compuesto principalmente de adipocitos, preadipocitos, macrófagos, células endoteliales, fibroblastos y leucocitos. Ha sido considerado como un depósito de combustible, conserva el calor del cuerpo y controla la movilización de lípidos. También juega un papel fundamental en la regulación metabólica sistémica como un órgano endocrino en el cual se sintetizan factores con funciones fisiológicas, denominados adipocinas.

Estos factores bioactivos secretados por el tejido adiposo transmiten información, a través de mecanismos endocrinos, a otros órganos metabólicamente activos, tales como músculo, hígado, páncreas y cerebro, modulando así el metabolismo sistémico.

Las adipocinas-citocinas relacionadas con la obesidad y trastornos metabólicos incluyen leptina, adiponectina, visfatina, apelina, vaspina, hepcidina, quelatina y omentina ${ }^{(18)}$.

Las complicaciones que desencadena el tejido adiposo están relacionadas con la hipertrofia del tejido, que bajo estas condiciones ejerce un proceso proinflamatorio leve que induce la mayoría de las complicaciones de la obesidad ${ }^{(19)}$.

Es relativamente reciente la consideración de la presencia de diferentes tipos de adipocitos en los adultos. La descripción de adipocitos con una función metabólica con tendencia a la producción de calor y una función mitocondrial mayor es llamativo y podría constituirse en un posible blanco terapéutico ${ }^{(20)}$.

\section{Tejido adiposo blanco (TAB/WAT)}

Los adipocitos blancos son células generalmente redondas, grandes, con un diámetro que varía de 25 a $200 \mathrm{~mm}$, que contienen una gran gota de triglicéridos, rodeada por una fina capa de citoplasma con pocas mitocondrias, y un núcleo aplanado situado en la periferia( ${ }^{(21)}$ (figura 2).

Figura 2. Capacidad termogénica de los adipocitos

Los adipocitos pardos tienen una coloración característica determinada por el contenido de mitocondrias. Los adipocitos beige tienen un contenido de mitocondrias menor, pero bajo estimulación de frío y otros factores tienen un efecto termogénico importante. Los adipocitos blancos almacenan energía en la forma de triglicéridos y no tienen capacidad termogénica. El

tamaño de los adipocitos es inverso a su función termogénica. El adipocito blanco está constituido por un solo compartimento graso que ocupa casi toda la célula. Los adipocitos beige pueden ser poliloculares, de menor tamaño y presencia de mitocondrias. El adipocito pardo es multilocular con un menor tamaño.

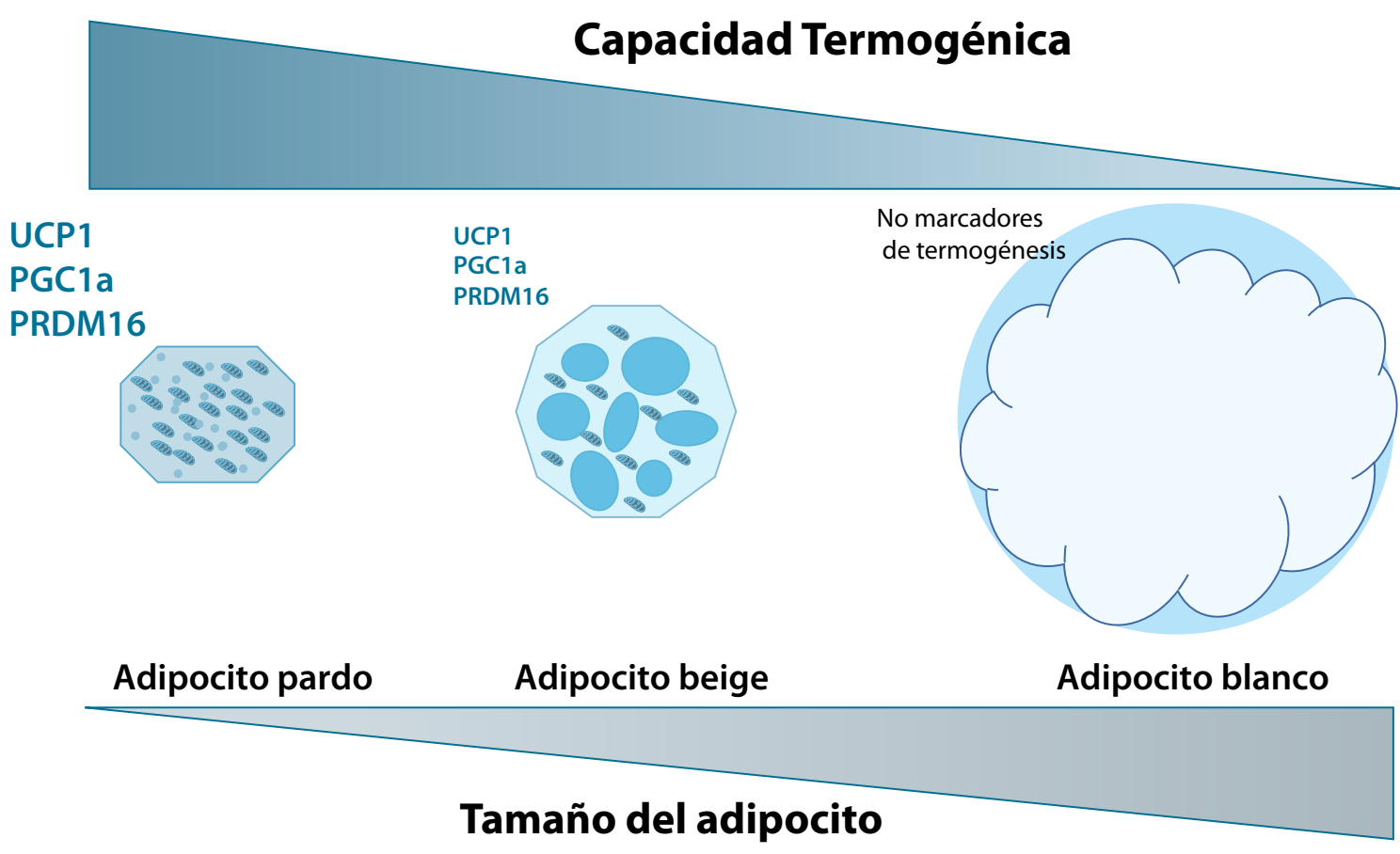


El desarrollo de TAB se inicia en el mesodermo durante el periodo embrionario. El origen de TAB proviene de diferentes depósitos: subcutáneo posterior, mesentérico y visceral perigonadal, mientras que los depósitos subcutáneo anterior $\mathrm{y}$ visceral retroperitoneal tienen un componente embrionario levemente diferente ${ }^{(22)}$.

$\mathrm{TAB}$, de acuerdo con la visión clásica, tiene como función proporcionar a largo plazo combustible metabólico durante circunstancias con necesidad calórica, como sería el caso del ayuno prolongado; esto lo realiza mediante el almacenamiento de triglicéridos ${ }^{(23)}$ y con la posterior liberación de ácidos grasos mediante la oxidación (lipólisis) que conlleva a mantener el equilibrio energético en el organismo.

Es también un órgano endocrino que secreta hormonas (incluyendo leptina, adiponectina, angiotensinógeno, factor de necrosis tumoral $\alpha(\mathrm{TNF} \alpha$ ), interleucina 6 (IL-6), resistina, etc.), con un papel importante en la regulación metabólica, los procesos inflamatorios y la homeostasis vascular ${ }^{(24)}$.

TAB se encuentra ampliamente distribuido en todo el cuerpo y representa alrededor del $10 \%$ al $20 \%$ del peso corporal en un individuo sano.

En el tejido adiposo blanco, el proceso de diferenciación implica la activación del factor de transcripción PPAR $\gamma$, que pertenece a la superfamilia de receptores nucleares y es el regulador central de la adipogénesis, relevante en todos los diferentes tipos de tejido adiposo ${ }^{(25)}$.

\section{Tejido adiposo pardo (TAP/BAT)}

Los adipocitos pardos son más pequeños que los adipocitos blancos y contienen gotas lipídicas multiloculares más pequeñas y muchas mitocondrias positivas para UCP1, que es una de las principales razones de su color característico.

Además de UCP1, se han descrito varios marcadores para los adipocitos pardos, incluyendo el coactivador $1 \alpha$ del receptor PPAR $\gamma$ (PGC- $1 \alpha$ ), activador de muerte celular (CIDEA), entre otros ${ }^{(26,27)}$. Los adipocitos pardos durante el desarrollo embrionario surgen del dermomiotoma central, y comparten su origen con las células del músculo esquelético, las células dérmicas, y una subpoblación de adipocitos blancos son todas positivas para el factor miogénico 5 (Myf5) ${ }^{(28)}$.

Históricamente se estimaba que TAP solo existía en los mamíferos hibernantes, posteriormente se determinó que es un tipo especial de órgano adiposo y se encuentra en casi todos los mamíferos, incluidos ratones, ratas, conejos, ovejas. Inicialmente en humanos se consideraba que este tejido solo estaba presente en los recién nacidos. En forma relativamente reciente, en el año 2009, se descubrió TAP funcional en adultos humanos ${ }^{(29-31)}$; se han observado cantidades significativas de TAP en la base del cuello en adultos humanos, y se puede activar mediante la exposición al frío. De hecho, la presencia de UCP1 es evidente en TAP de pacientes con feocromocitoma e hibernoma mediante tomografía de emisión de positrones
F-fluorodeoxiglucosa (F-FDG) fusionada a tomografía computarizada.

Luego del descubrimiento de TAP en los seres humanos adultos, algunas de sus propiedades están siendo manifiestas en varios estudios, tal como la correlación inversa con el índice de masa corporal (IMC), mejoría de la resistencia a insulina, cambio del proceso inflamatorio y una alta vascularización para permitir la transferencia del efecto termogénico ${ }^{(31)}$.

Durante el desarrollo de TAP, se han identificado hasta ahora algunos reguladores positivos, incluyendo proteína con dominio PR de dedos de zinc 16 (PRDM16), PPAR $\alpha$, proteína morfogenética ósea 7 (BMP7) y orexina. Se demostró que PRDM16 es necesaria para mantener la función de TAP durante la diferenciación. Así mismo, PRDM16 forma complejos con otros factores reguladores, incluyendo PPAR $\gamma, \mathrm{PGC}-1 \alpha$, proteínas de unión a C-terminal (CtBPs) y factor temprano de células B (EBF2) ${ }^{(26)}$.

En comparación con TAB, los adipocitos, el TAP es bastante vascularizado e inervado, lo que permite una rápida estimulación de la membrana adipocitaria. Por ejemplo, en condiciones de frío, el hipotálamo impulsa la liberación de norepinefrina (NE) mediante la activación del sistema nervioso simpático, que posteriormente activa el receptor adrenérgico (AR) que se acopla a las proteínas G 7-transmembrana.

\section{Tejido adiposo beige/brite}

El tejido adiposo beige/brite, que también se conoce como tejido adiposo marrón inducible, proceso al que se denomina Beigeing o Browning, funciona como un tejido adiposo de reserva y termogénico ${ }^{(20)}$.

Los adipocitos beige se dispersan entre los adipocitos blancos y son morfológicamente similares a un adipocito pardo clásico que contiene gotas lipídicas multiloculares, pero variables en tamaño, y con muchas mitocondrias positivas para UCP1 ${ }^{(32)}$.

Las células beige expresan genes específicos presentes en la grasa parda, incluyendo UCP1 y también sufren termogénesis a través del desacoplamiento de la fosforilación oxidativa de la producción de ATP.

No hay consenso en cuanto al mecanismo de beigeing y el origen embrionario de los adipocitos beige. Mientras la mayoría de los adipocitos pardo surgen de las células multipotentes del dermomiotoma, los adipocitos beige se originan de precursores mesenquimatosos ${ }^{(33)}$.

Algunos de los adipocitos beige surgen de células endoteliales y perivasculares dentro del tejido adiposo blanco con una firma génica única, son células Myf5-negativas que parecen originarse en forma diferente de los adipocitos blanco y marrón. Estos adipocitos preexistentes expresan su fenotipo más termogénico mediante la exposición al frío o la estimulación farmacológica mediante estimulación de b3-adrenérgica ${ }^{20,32-34)}$. La exposición crónica al frío en los ratones induce una cantidad 
sustancial de adipocitos beige que se originan de los adipocitos diferenciados de novo en los depósitos de grasa subcutánea, retroperitoneal y perigonadal posterior ${ }^{(35)}$.

PRDM 16 y PPAR $\alpha / \gamma$ desempeñan papeles críticos en el desarrollo de células beige. Se ha demostrado que su efecto regulador positivo está relacionado con una inducción en la expresión de PGC-1 $\alpha^{(36)}$ y una interacción estable de PRDM16 y PPAR $\gamma$, que podría ser promovida por una desacetilación dependiente de sirtuina 1 (SIRT1) sobre PPAR $\gamma^{(37)}$.

En general, bajo condiciones basales, los adipocitos beige expresan bajos niveles de UCP1, pero a la estimulación adrenérgica inducida por la exposición al frío, el ejercicio y muchos factores y cofactores intrínsecos de transcripción, desencadenan activamente la biogénesis termogénica del adipocito beige; en estas condiciones los adipocitos beige producen altas cantidades de UCP1 ${ }^{(32,38)}$ (figura 2).

\section{Cambios epigenéticos en el tejido adiposo}

Los cambios epigenéticos que controlan la actividad de las células adiposas son más evidentes en las modificaciones del patrón de metilación del ADN en algunos de los genes reguladores de la adipogénesis (figura 3).

\section{Patrones de metilación del ADN}

La metilación es resultado de la adición de un grupo metilo a una citosina posicionada junto a un nucleótido de guanina (CpGs), en regiones con una elevada concentración (>60\%) de dinucleótidos CpG. La metilación en una región promotora da lugar a la represión (silenciamiento) de la expresión génica a través de una serie de mecanismos que incluyen: obstrucción del acceso a factores de transcripción, coactivadores de transcripción $^{(39,40)}$.

El patrón de metilación del ADN tiene un papel relevante en la regulación de genes claves implicados en regular la homeostasis de la glucosa. Por ejemplo, el promotor del gen de la insulina (INS) se encuentra "desmetilado" en las células beta de los islotes pancreáticos ${ }^{(41)}$. El transportador de glucosa 4 (GLUT 4) que se transloca a la membrana plasmática en respuesta a la insulina ${ }^{(40)}$ está desmetilado en los adipocitos diferenciados, mientras en los adipocitos hipertróficos el nivel de metilación aumenta. De forma similar, el gen del receptor nuclear PPAR $\gamma 2$ progresivamente se va desmetilando en adipocitos diferenciados, lo que proporciona evidencia de que la metilación del ADN establece la expresión génica específica del adipocito ${ }^{(42)}$.

Tanto la hipermetilación del promotor de PPAR $\gamma 2$ (-437CpG), como de la zona reguladora del gen de POMC han sido observadas en modelos múridos con obesidad, así como para FTO; MC4R y leptina ${ }^{(39,43,44)}$.

En un estudio en humanos se investigó el patrón de metilación del ADN y los cambios en la expresión génica en el tejido adiposo subcutáneo de las mujeres posmenopáusicas obesas/ con sobrepeso antes y después de una dieta de restricción calórica de seis meses. Las participantes se agruparon en respondedoras altas y bajas a la dieta de acuerdo con los cambios en el porcentaje de grasa corporal después de completar el experimento. La valoración del patrón de metilación de leptina y TNF- $\alpha$ en el tejido adiposo subcutáneo humano fue estudiada previamente y luego de una dieta restrictiva. Se observó que el patrón de metilación de las personas que respondían a la dieta presentaba un patrón de metilación más bajo que las personas que no tenían una buena respuesta a la dieta ${ }^{(45)}$. Hecho que sugiere que el nivel de metilación de los promotores de leptina y TNF- $\alpha$ puede ser un predictor epigenético de la capacidad de respuesta a una dieta de restricción calórica ${ }^{(46)}$.

Después de un análisis de 450 millones de sitios CpG y posterior validación en otras dos cohortes diferentes, ${ }^{(47)}$ fue asociado el aumento del IMC y la adiposidad con la hipermetilación del gen del factor de transcripción inducible por hipoxia A (HIF A). En otro estudio de Feinberg et al. 2010, ${ }^{(48)}$ se analizaron 4 millones de sitios $\mathrm{CpG}$ en 74 individuos para la búsqueda de regiones metiladas variables que podrían utilizarse en el pronóstico del riesgo de enfermedad. Se describen cuatro regiones asociadas con el IMC, situado cerca de genes relacionados con la regulación del peso corporal y la diabetes.

\section{Modificaciones de las histonas}

La supresión de la actividad de la histona desmetilasa JHDM2A aumenta la susceptibilidad a la obesidad, debido a una reducción de la función de PPAR $\gamma^{(49)}$. Nosotros observamos en células 3T3-L1, que la desmetilasa de histonas JMJD2C modula la actividad de PPAR $\gamma$ y reduce la adipogénesis ${ }^{(50)}$. En otros estudios en los que se valoraron las desmetilasas de histonas en eventos metabólicos, se han encontrado modificaciones de las histonas en especial por las desmetilasas LSD1 y JHDM1E ${ }^{(43)}$.

Un estudio comparó la expresión de proteínas en los mononucleares y el tejido adiposo subcutáneo de individuos obesos y delgados luego de actividad física. Dentro de las proteínas que presentaban una modificación más significativa se encontraba la desacetilasa de histonas 4 (HDAC4), con un papel protector para la aparición de la obesidad ${ }^{(51)}$.

Un represor de la transcripción TRIM28/KAP1 (proteína asociada a KRAB-1), el cual regula la formación de heterocromatina, se encuentra disminuido en individuos obesos, incluso en niños gemelos que presentan diferente peso la expresión de esta proteína fue observada reducida en los que tenían un peso mayor. Es posible que este factor de la transcripción actúe como un regulador epigenético del metabolismo ${ }^{(52)}$ (figura 3).

\section{ARN de interferencia}

Las modificaciones epigenéticas inducidas por los ARNi son menos reconocidas y de conocimiento más reciente. No obstante, un aumento de la actividad de miR-483-3p ha sido observado en individuos sanos en relación con los obesos en 
Figura 3. Nivel de expresión génica

La presencia de ADN "desnudo" tiene la facultad de que los factores de la transcripción puedan influir en la mayor expresión de genes. Cuando el ADN está íntimamente asociado a las histonas, en los nucleomas, la probabilidad de expresar genes se ve reducida en la medida en que la unión es más estrecha. Es nula con la formación de los cromátides.

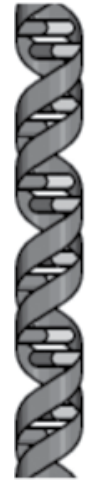

ADN

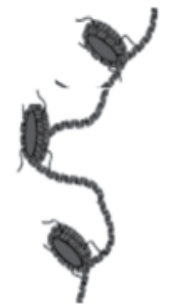

ADN

$+$ nucleosoma
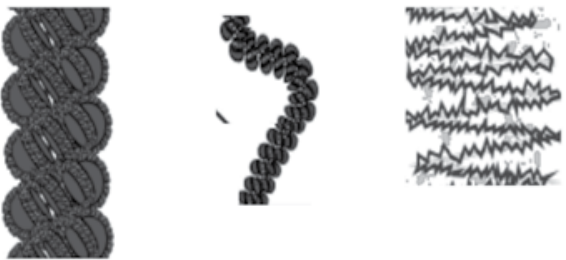

Nucleosomas empaquetados
Organización

de la cromatina

ADN+ nucleosoma

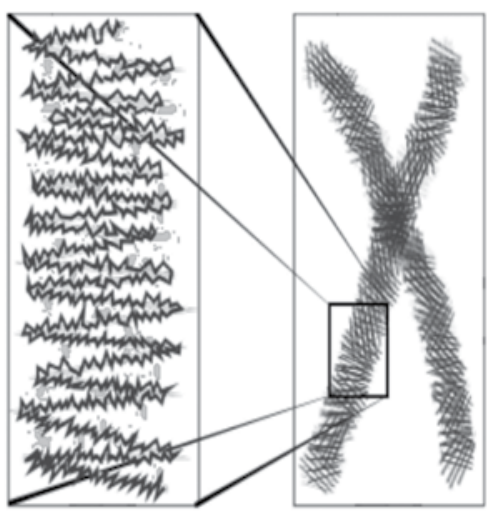

Formación de cromosomas los adipocitos subcutáneos. La acción de miR-483-3p está relacionada con la regulación de la expresión del gen que codifica para la proteína GDF3 (factor de crecimiento diferenciador 3) un miembro de la familia de TGF- $\alpha$, el cual modula el proceso de la adipogénesis ${ }^{(53)}$.
En estudios en cultivos primarios de adipocitos humanos se observó que la inhibición de miR-143 aumenta la adipogénesis mediante una elevación de la actividad de una cinasa mitogénica denominada ERK5 (cinasa 5 regulada por señal extracelular) ${ }^{(54)}$ (tabla 1).

Tabla 1. Algunos factores nutricionales que tienen efecto metabólico mediante la modulación de eventos epigenéticos

\begin{tabular}{c|l|l}
\hline \multicolumn{1}{c|}{ Factor nutricional } & \multicolumn{1}{c}{ Condición metabólica } & Mecanismo epigenético \\
Donadores de grupos metilo & \multicolumn{1}{c}{ Metilación de histonas y ADN } \\
\multicolumn{1}{c|}{ Betaina (trimetilglicina) } & Resistencia a la insulina, Esteatosis hepática & Metilación de histonas y ADN \\
\hline Colina & Esteatosis hepática & Metilación del ADN \\
\hline Ácido fólico & Resistencia a la insulina, adipogénesis & Metilación de histonas y ADN \\
\hline Metionina & Resistencia a la insulina, obesidad & Metilación del ADN \\
\hline Vitamina B-12 & Resistencia a la insulina, obesidad & Acetilación de histonas, metilación ADN y ARNi. \\
\hline Fitoquimicos & Inflamación y obesidad & Acetilación de histonas, metilación ADN \\
\hline Curcumina & Obesidad, resistencia a la insulina y Esteatosis hepática & Acetilación de histonas, metilación ADN \\
\hline Epigallocatequina 3 & Obesidad & Acetilación de histonas \\
\hline Genisteina & Obesidad y esteatosis hepática & Acetilación de histonas \\
\hline Resveratrol & Diferenciación de adipocito & Acetilación de histonas y propionilación \\
\hline Sulforafano & & Resistencia a la insulina, inflamación \\
\hline Ácidos grasos & Ácido butírico y otros SCFAs & \\
\hline
\end{tabular}




\section{Conclusión}

Los estudios recientes han aportado una importante información acerca de los mecanismos moleculares mediante los cuales el ambiente puede generar cambios en la expresión de genes que controlan muchas vías metabólicas que están comprometidas en el origen de la obesidad y la diabetes mellitus. Los patrones de metilación del ADN en los CpG de las zonas controladoras de la expresión de los genes y los polimorfismos en varios genes son unos avances importantes con los secuenciadores de última generación. Las variaciones epigenéticas determinadas por las modificaciones de las histonas y los RNAi son más complejas de estudiar, pero su influencia en la adaptación del individuo a condiciones alimentarias, la pre- sencia de una microbiota especifica o la influencia de disruptores endocrinos (productos químicos) son puntos concretos en los que las modificaciones de las histonas pueden ser claves en posibles enfoques terapéuticos para evitar las condiciones que induzcan estos desórdenes metabólicos.

\section{Agradecimientos}

Especialmente agradecimientos al programa de posgrados de la Facultad de Medicina y a la dirección de Investigación de la Universidad de la Sabana por su apoyo con el proyecto MED-181-2014. A todo el equipo del laboratorio CIBUS, quienes han intervenido críticamente en este trabajo.

\section{Referencias}

1. Ng M, Fleming T, Robinson M, Thomson B, Graetz N, Margono C, et al. Global, regional, and national prevalence of overweight and obesity in children and adults during 1980-2013: a systematic analysis for the Global Burden of Disease Study 2013. The Lancet. 2014;384(9945):766-81.

2. Kelly T, Yang W, Chen CS, Reynolds K, He J. Global burden of obesity in 2005 and projections to 2030. Int J Obes (Lond). 2008;32(9):1431-7.

3. Ogden CL, Carroll MD, Fryar CD, Flegal KM. Prevalence of Obesity Among Adults and Youth: United States, 2011-2014. NCHS Data Brief. 2015(219):1-8.

4. Gregg EW, Shaw JE. Global Health Effects of Overweight and Obesity. N Engl J Med. 2017.

5. Urbina EM, Gidding SS, Bao W, Elkasabany A, Berenson GS. Association of fasting blood sugar level, insulin level, and obesity with left ventricular mass in healthy children and adolescents: The Bogalusa Heart Study. Am Heart J. 1999;138(1 Pt 1):122-7.

6. Farooqi S, O'Rahilly S. Genetics of obesity in humans. Endocr Rev. 2006;27(7):710-18.

7. Fall T, Mendelson M, Speliotes EK. Recent Advances in Human Genetics and Epigenetics of Adiposity: Pathway to Precision Medicine? Gastroenterology. 2017;152(7):1695-706.

8. Nan C, Guo B, Warner C, Fowler T, Barrett T, Boomsma D, et al. Heritability of body mass index in pre-adolescence, young adulthood and late adulthood. Eur J Epidemiol. 2012;27(4):247-53.

9. Waddington CH. The epigenotype. 1942. Int J Epidemiol. 2012;41(1):10-3.

10. Bird A. Perceptions of epigenetics. Nature. 2007;447(7143):396-8.

11. Reddy MA, Natarajan R. Epigenetic mechanisms in diabetic vascular complications. Cardiovasc Res. 2011;90(3):421-9.

12. Campion J, Milagro F, Martinez JA. Epigenetics and obesity. Prog Mol Biol Transl Sci. 2010;94:291-347.

13. Miranda TB, Jones PA. DNA methylation: the nuts and bolts of repression. J Cell Physiol. 2007;213(2):384-90.

14. Egger G, Liang G, Aparicio A, Jones PA. Epigenetics in human disease and prospects for epigenetic therapy. Nature. 2004;429(6990):457-63.

15. Cedar H, Bergman Y. Linking DNA methylation and histone modification: patterns and paradigms. Nat Rev Genet. 2009;10(5):295-304.

16. Hammond SM. Dicing and slicing: the core machinery of the RNA interference pathway. FEBS Lett. 2005;579(26):5822-9.

17. Humphreys DT, Westman BJ, Martin DI, Preiss T. MicroRNAs control translation initiation by inhibiting eukaryotic initiation factor 4E/cap and poly(A) tail function. Proc Natl Acad Sci U S A. 2005;102(47):16961-6.

18. Coelho M, Oliveira T, Fernandes R. Biochemistry of adipose tissue: an endocrine organ. Arch Med Sci. 2013;9(2):191-200.

19. Yang H, Youm YH, Vandanmagsar B, Ravussin A, Gimble JM, Greenway $\mathrm{F}$, et al. Obesity increases the production of proinflammatory mediators from adipose tissue T cells and compromises TCR repertoire diversity: implications for systemic inflammation and insulin resistance. J Immunol. 2010;185(3):1836-45

20. Lizcano F, Vargas D. Biology of Beige Adipocyte and Possible Therapy for Type 2 Diabetes and Obesity. Int J Endocrinol. 2016;2016:9542061.

21. Vargas D, Shimokawa N, Kaneko R, Rosales W, Parra A, Castellanos A, Koibu- chi N, Lizcano F. Regulation of Human subcuataneous adipocyte differentiation by EID1. J Mol Endocrinol. 2016;56:113-22..

22. Sanchez-Gurmaches J, Guertin DA. Adipocytes arise from multiple lineages that are heterogeneously and dynamically distributed. Nat Commun. 2014;5:4099.

23. Langin D. Recruitment of brown fat and conversion of white into brown adipocytes: strategies to fight the metabolic complications of obesity? Biochimica et biophysica acta. 2010;1801(3):372-6.

24. Trayhurn P, Beattie JH. Physiological role of adipose tissue: white adipose tissue as an endocrine and secretory organ. Proc Nutr Soc. 2001;60(3):329-39.

25. Willson TM, Brown PJ, Sternbach DD, Henke BR. The PPARs: from orphan receptors to drug discovery. J Med Chem. 2000;43(4):527-50.

26. Shinoda K, Luijten IH, Hasegawa Y, Hong H, Sonne SB, Kim M, et al. Genetic and functional characterization of clonally derived adult human brown adipocytes. Nat Med. 2015;21(4):389-94.

27. Sidossis L, Kajimura S. Brown and beige fat in humans: thermogenic adipocytes that control energy and glucose homeostasis. J Clin Invest. 2015;125(2):478-86.

28. Seale P, Bjork B, Yang W, Kajimura S, Chin S, Kuang S, et al. PRDM16 controls a brown fat/skeletal muscle switch. Nature. 2008;454(7207):961-7.

29. Enerback S. The origins of brown adipose tissue. $\mathrm{N}$ Engl J Med. 2009;360(19):2021-3.

30. Cypess AM, Lehman S, Williams G, Tal I, Rodman D, Goldfine AB, et al. Identification and importance of brown adipose tissue in adult humans. N Engl J Med. 2009;360(15):1509-17.

31. Virtanen KA, Lidell ME, Orava J, Heglind M, Westergren R, Niemi T, et al. Functional brown adipose tissue in healthy adults. $\mathrm{N}$ Engl J Med. 2009;360(15):1518-25.

32. Wu J, Bostrom P, Sparks LM, Ye L, Choi JH, Giang AH, et al. Beige adipocytes are a distinct type of thermogenic fat cell in mouse and human. Cell. 2012;150(2):366-76.

33. Long JZ, Svensson KJ, Tsai L, Zeng X, Roh HC, Kong X, et al. A smooth musclelike origin for beige adipocytes. Cell Metab. 2014;19(5):810-20.

34. Lee YH, Petkova AP, Mottillo EP, Granneman JG. In vivo identification of bipotential adipocyte progenitors recruited by beta3-adrenoceptor activation and high-fat feeding. Cell Metab. 2012;15(4):480-91.

35. Rosenwald M, Perdikari A, Rulicke T, Wolfrum C. Bi-directional interconversion of brite and white adipocytes. Nat Cell Biol. 2013;15(6):659-67.

36. Hondares E, Mora O, Yubero P, Rodriguez de la Concepcion M, Iglesias R, Giralt $\mathrm{M}$, et al. Thiazolidinediones and rexinoids induce peroxisome proliferator-activated receptor-coactivator (PGC)-1alpha gene transcription: an autoregulatory loop controls PGC-1alpha expression in adipocytes via peroxisome proliferator-activated receptor-gamma coactivation. Endocrinology. 2006;147(6):2829-38.

37. Qiang L, Wang L, Kon N, Zhao W, Lee S, Zhang Y, et al. Brown remodeling of white adipose tissue by SirT1-dependent deacetylation of Ppargamma. Cell. 2012;150(3):620-32.

38. Kajimura S, Spiegelman BM, Seale P. Brown and Beige Fat: Physiological Roles beyond Heat Generation. Cell Metab. 2015;22(4):546-59. 
39. Herrera BM, Keildson S, Lindgren CM. Genetics and epigenetics of obesity. Maturitas. 2011;69(1):41-9.

40. Barres R, Zierath JR. DNA methylation in metabolic disorders. Am J Clin Nutr. 2011;93(4):897S-900.

41. Kuroda A, Rauch TA, Todorov I, Ku HT, Al-Abdullah IH, Kandeel F, et al. Insulin gene expression is regulated by DNA methylation. PLoS One. 2009;4(9):e6953.

42. Fujiki K, Kano F, Shiota K, Murata M. Expression of the peroxisome proliferator activated receptor gamma gene is repressed by DNA methylation in visceral adipose tissue of mouse models of diabetes. BMC Biol. 2009;7:38.

43. Kasinska MA, Drzewoski J, Sliwinska A. Epigenetic modifications in adipose tissue - relation to obesity and diabetes. Arch Med Sci. 2016;12(6):1293301.

44. Malodobra-Mazur M, Dziewulska A, Kozinski K, Dobrzyn P, Kolczynska K, Janikiewicz J, et al. Stearoyl-CoA desaturase regulates inflammatory gene expression by changing DNA methylation level in 3T3 adipocytes. Int J Biochem Cell Biol. 2014;55:40-50.

45. Bouchard L, Rabasa-Lhoret R, Faraj M, Lavoie ME, Mill J, Perusse L, et al. Differential epigenomic and transcriptomic responses in subcutaneous adipose tissue between low and high responders to caloric restriction. Am J Clin Nutr. 2010;91(2):309-20.

46. Cordero P, Campion J, Milagro FI, Goyenechea E, Steemburgo T, Javierre $\mathrm{BM}$, et al. Leptin and TNF-alpha promoter methylation levels measured by MSP could predict the response to a low-calorie diet. J Physiol Biochem. 2011;67(3):463-70
47. Dick KJ, Nelson CP, Tsaprouni L, Sandling JK, Aissi D, Wahl S, et al. DNA methylation and body-mass index: a genome-wide analysis. Lancet. 2014;383(9933):1990-8.

48. Feinberg AP, Irizarry RA, Fradin D, Aryee MJ, Murakami P, Aspelund T, et al. Personalized epigenomic signatures that are stable over time and covary with body mass index. Sci Transl Med. 2010;2(49):49ra67.

49. Tateishi K, Okada Y, Kallin EM, Zhang Y. Role of Jhdm2a in regulating metabolic gene expression and obesity resistance. Nature. 2009;458(7239):75761.

50. Lizcano F, Romero C, Vargas D. Regulation of adipogenesis by nuclear receptor PPARgamma is modulated by the histone demethylase JMJD2C. Genet Mol Biol. 2011;34(1):19-24.

51. Abu-Farha M, Tiss A, Abubaker J, Khadir A, Al-Ghimlas F, Al-Khairi I, et al. Proteomics analysis of human obesity reveals the epigenetic factor HDAC4 as a potential target for obesity. PLoS One. 2013;8(9):e75342.

52. Dalgaard K, Landgraf K, Heyne S, Lempradl A, Longinotto J, Gossens K, et al. Trim28 Haploinsufficiency Triggers Bi-stable Epigenetic Obesity. Cell. 2016;164(3):353-64.

53. Ferland-McCollough D, Fernandez-Twinn DS, Cannell IG, David H, Warner M, Vaag AA, et al. Programming of adipose tissue miR-483-3p and GDF-3 expression by maternal diet in type 2 diabetes. Cell Death Differ. 2012;19(6):1003-12.

54. Esau C, Kang X, Peralta E, Hanson E, Marcusson EG, Ravichandran LV, et al. MicroRNA-143 regulates adipocyte differentiation. J Biol Chem. 2004;279(50):52361-5.

\section{6 al 29 de abril de 2018}

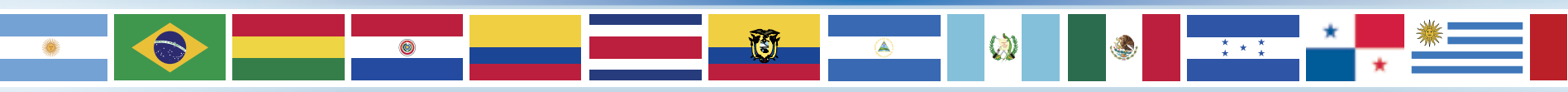

\section{Congreso Latinoamericano de Endocrinología}

\section{Cartagena}

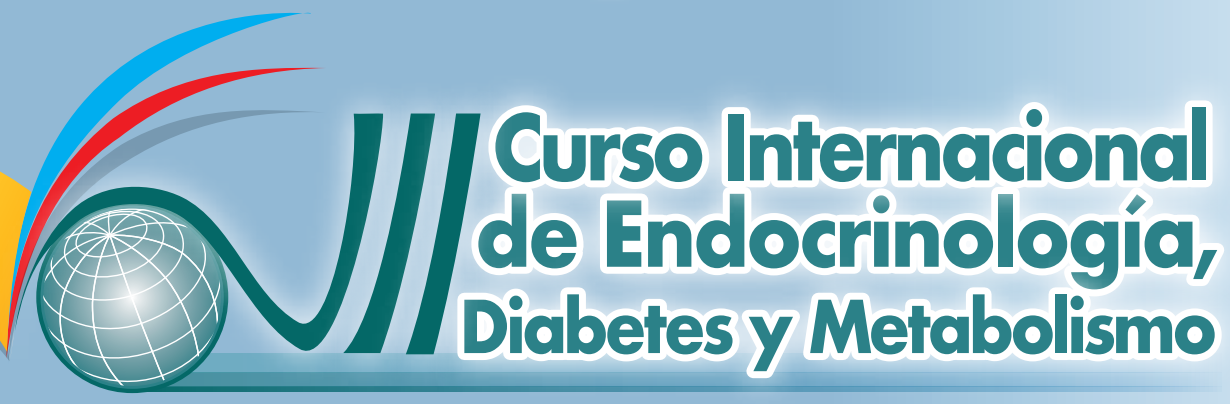

@ENDOCRINO_COL
ínea Gratuita Nacional:
018000110113

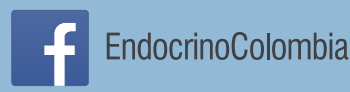

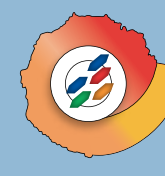

Teléfonos:

(00571) 6420243-6420245

\section{Asociación Colombiana \\ de Endocrinología, \\ Diabetes y Metabolismo \\ Fundada en 1950}

e-mail:

noticias@endocrino.org.co 